\title{
Guest Editorial: Mediterranean Nanophotonics
}

\author{
Zeev Zalevsky \\ Bar-Ilan University, School of Engineering, Ramat-Gan 52900, Israel \\ zalvesz@eng.biu.ac.il \\ Ekmel Ozbay \\ Bilkent University, Nanotechnology Research Center (NANOTAM), Bilkent, Ankara 06800, Turkey \\ ozbay@bilkent.edu.tr \\ Ibrahim Abdulhalim \\ Ben-Gurion University, Electro-optics Engineering, Beer-Sheva 84105, Israel \\ abdulhlm@bgu.ac.il \\ Nanophotonics is one of the hottest research topics relevant for a large variety of academic as \\ well industrial applications. The main advantage of this field is in developing devices, \\ fabrication techniques and sensing approaches with increased multi-functionality, higher level \\ of integration, faster rate of operation, lower consumption of energy, smaller dimensions and \\ reduced cost. \\ The first Mediterranean conference on nanophotonics (MediNano-1) was organized in \\ Istanbul, Turkey on October 6-7, 2008. More than 150 participants from more than 20 \\ countries presented their work. The purpose of this conference was to generate a closer \\ collaboration link in the field of nanophotonics between research facilities, institutes, \\ industries and, of course scientists, from the Mediterranean countries and to establish a \\ tradition of future conferences in this field. \\ This special section in the Journal of Nanophotonics contains a selection of papers \\ presented at the conference. These peer-reviewed papers contain research work on integrated \\ sensors, sensing and characterization techniques, integrated modulation devices and \\ fabrication approaches. We, the guest editors of this special section, hope that the tradition of \\ MediNano conferences (the meeting of 2009 was recently held in Athens, Greece) will be \\ even stronger in the coming years.
}

